\title{
Creative Nature of the Ideal in Culture
}

\author{
Viktor Ivanovich Polishchuk ${ }^{1}$, Zoya Yanovna Selitskaya² \& Grigory \\ Viktorovich Silchenko ${ }^{3}$
}

${ }^{1}$ Professor, Chair of Russian and foreign philology, cultural science and technique of their teaching, Socially-humanitarian faculty, Tyumen State University, 10 Semakova Str., Tyumen, 625003, Russia Email:v.i.p.1945@mail.ru.

${ }^{2}$ Managing chair of Russian and foreign philology, cultural science and a technique of their teaching, is Senior Lecturer, Socially-humanitarian faculty, Tyumen State University, 10 Semakova Str., Tyumen,625003, Russia, Email: kelberer_gr@mail.ru.

${ }^{3}$ Senior Teacher of chair of Russian and foreign philology, cultural science and technique of their teaching, Socially-humanitarian faculty, Tyumen State University, 10 Semakova Str., Tyumen, 625003, Russia, Email: grishanja1982@mail.ru.

Received April 11, 2016; Revised July o7, 2016; Accepted July 10, 2016; Published August 18, 2016

\begin{abstract}
The article deals with the notion of the "ideal", its correlation with the notions of "idea", "appearance", "form", "image", "seeing". The article analyses the contribution to the study made by the Russian philosophers Vladimir Solovyev and Evald Ilyenkov. The authors of the article argue that although they define the ideal differently, both thinkers identify it with the purpose of societal development, culture and history. The article reveals the mutual linkage of such notions as the ideal, the idol and the visibility. The fundamental problem of the discussion lies in determining the source of the ideal. The article uses the rules of deductive and inductive logic, the required analytical procedures, as well as diachronic, comparativehistorical, hermeneutic and phenomenological methods. The authors come to the following relevant conclusions: firstly, the ideal has a dual nature, which accounts for a tendency to identify it with the idol; secondly, childhood experience is the essential source of the ideal.
\end{abstract}

Key words: culture, history, ideal, structure of ideal, idea, idol, appearance, visibility, creation, propensity for the past.

The word "ideal" appeared in the European languages comparatively recently. It was not used in antiquity; it was sufficient for the ancient Greeks to use the term í $\delta$ ź (idea) that has a synonymic meaning, which sounded similarly in Latin: idea. However, the adjective "ideal" appeared in PostLatin. The word "ideal" dates back to it; at first it gained popularity in German philosophical terminology, and then in everyday language.

In German classics, the problem of ideal was touched upon by Kant in connection with the problem of "inner purpose". However, Shelling used the notion of ideal as a synonym to outer purpose, general for all representatives of humanity. Developing his own understanding of history, he wrote in the System of Transcendentalism (180o) that there is the history of people, who see an ideal as "inaccessible for an individuum, but accessible for the generation". Consequently, history, for Shelling, is the subsequent implementation of "never lost ideal", i.e.

(c) AesthetixMS 2016. This Open Access article is published under a Creative Commons Attribution Non-Commercial 4.0 International License (http://creativecommons.org/licenses/by-nc/4.o/), which permits non-commercial re-use, distribution, and reproduction in any medium, provided the original work is properly cited. For citation use the DOI. For commercial re-use, please contact editor@rupkatha.com. 
approximation to the purpose, which, however, "remains the eternal credo of creating and acting man" (Shelling, 1987).

In his Phänomenologie des Geistes (1909), Hegel wrote about the ideal more definitely, "it is an idea, seen on the part of its existence, corresponding to the notion". The ideal, or the phenomenon of idea, is "any activity in its highest truth" (Hegel, 1909). However, the idea is the reality, corresponding not to any outside notion, but to its own. The difference is slight, but significant: an ideal is an apparent idea, and an idea is an invisible ideal. The root "appearance", general for the Indo-European languages, is used here in different meanings; in Old Greek it formed the words "visibility", "appearance", "outward appearance", "form", "image", including "idea". This root forms the Russian word "to see". In other words, the reasoning about an idea or an ideal has the invisible corresponding human ability (Note 1).

Thus, the idea is a pure view of something, any object, deprived of corporality, substantively, materiality. This absence of everything, including the content, makes it invisible, in the common sense of this word. There remains only the "bare" form, pure existence of an object or its "appearance", as a human ability to perceive such existence, i.e. to see. Consequently, an ideal is the result of implementation of an idea, when the truth of existence, according to Hegel, is the essence, thus becoming the visibility.

In Russian philosophy, the problem of the ideal found the most comprehensive treatment in the well-known works of Vladimir Solovyev (Idols and Ideals, 1891) and Evald Ilyenkov (On Idols and Ideals, 1968). This problem did not become the focus of their attention simultaneously, that is why the reasons for them to address the topic of the ideal were different. However, the problem under consideration being the same, the pronounced opinions also had a lot in common. V.S. Solovyev defined the ideal as an inherent value equally required for everybody, which possesses the inner absolute merit. It was natural for him to connect the ideal with faith, i.e. with the state of soul, worshiping the eternal God. Full implementation of a Christian ideal of "universal solidarity and free development of all living human forces", in the thinker's opinion, is the finite purpose of history, and the "many-sided development of culture" shall be the general and required means to achieve this purpose (Solovyev, 1995). To work in this direction is "the task of the educated class", its devotion to an ideal. The devotion to something less sublime, worship of something limited, including "the common people", is nothing but "idolization" (Solovyev, 1995).

E.V. Ilyenkov, following the Hegelian tradition, which was developed in Marxism, understood an ideal as not a static image, but as a movement towards the purpose. In such movement, an ideal is substantiated by means of activity, gradually acquiring the traits of communist regime. The deviations of the activity from the theoretic standard (image of the purpose) are possible on the way to an ideal. However, such deviations present the way to "implement general ideal, it is the ideal itself" (Ilyenkov, 1968) - a community of free people deprived of oppressive contradictions; their life activity is not regulated by anything "external". An ideal is in human life, but not in its product. The latter becomes an idol if it rises above human (Ilyenkov, 1986).

It is clear from the above that E.V. Ilyenkov bore in mind, first of all, a social ideal, which is primarily relevant to a community of people. It is also clear, that the structure of human activity predetermines not only a sensual and objective character of the ideal, but also its universality, as an expression of unity of the varied demands and interests. The philosopher wrote about an individual ideal when he dealt with the problems of the formation of thinking, artistic imagination, and art in particular. Here he identified the ideal with beauty and freedom (1986). 
Thus, defining the ideal differently, both thinkers are similar in its identification with the purpose of the development of society, culture and history. They share a view on the correlation of ideals and idols. An idol is a substitution of an ideal, even in thoughts, i.e. something fictitious. Its merit is intentionally below its creator - the man. Worshipping an idol is the source of humiliation, injustice and evil, whereas an ideal is the source of kindness, freedom and creativity. Only the question about the source of an ideal itself remains open.

Nonetheless, the ideal should be neither equated with purpose nor seen in the future. It would be possible to agree with such identification if only the social ideal were considered. However, a clarification is also necessary here. On the one hand, it is typical of human beings, dissatisfied with the present, to wish for the best, hoping for future. On the other hand, the future can bring new problems and contradictions. It is well seen in the history of the Russian society, which repeatedly tried to "jump" into the future, rejecting the past as something frustrating. That is why the meaning of "a social ideal", applied to real society, is twofold: it either expresses the general tendency to idealize the future, or, as a notion, substitutes the enforced view of the future as the very aim of the ongoing social changes. The notorious "Russian idea" is a good example of how all attempts to express the essence, the mission of the Russian nation, were based on the effort to define its purpose. Let us say, if we use the word "ideal" instead of "idea", we will have to speak not so much about the future, but about the past of Russia, as romanticists or Slavophiles did, or about the state of unconcern and idleness so desirable to a Russian person. With regard to the future, nothing but the purpose of the society can be real. As an anticipation of the desired outcome, the purpose is doubtless idealistic, but it does not equal to the ideal.

As seen from the discussion above, the ideal can be regarded as a potential value or a quality of a person. The wise men of ancient Greece knew about it. They left their commandments as the views on the life ideals. In other words, although there was no any notion of an "ideal" in antiquity, the corresponding views still existed. In mythopoetic form, they present the bright illustration to the transformation of an idea into an ideal, presented in the German classics. Such is the myth about Pygmalion, a famous sculptor and tsar of Cyprus. Not finding a girl, who could correspond to his view of an ideal woman, he made a statue of a girl called Galatea. He fell in love with her before she was sculptured, as each of us loves and cherishes his ideal. Naturally, he continued to love the created image of his ideal. It seemed to him that the statue was different from the ideal only in that it was inanimate. Pygmalion begged the Gods to make her alive. Aphrodite replied to his worship; she was not indifferent to the Cypriots, especially, if the matter was connected with love. The Divinity made the statue alive on the condition, that Pygmalion will still love Galatea. Otherwise, the girl will turn into the statue again.

Pygmalion and Galatea were happy for a long time as a married couple. However, once Pygmalion found Galatea's wish - something ordinary and innocent - to be a whim and he hit her in irritation. As it was promised, she became a stone again.

It is almost a common everyday story. However, its meaning is not limited, certainly, by troubles of family life. The myth deals with the events, which, paraphrasing Shelling, are much more real, than what is called real in everyday life. It is "a greater reality" of mythic narrations, that they symbolize general logics of human actions not only in similar situations, but also in all possible ones. The myth about Pygmalion narrates about the fate of a creator and his creation. In a wider sense, it is about the correlation of an ideal and its man-made implementation. It also deals with the occurring dissatisfaction of a creator with his creation which was, as he supposed, ideal. It is obvious, that Pygmalion became dissatisfied with Galatea. It is less obvious, that he was dissatisfied with himself, as an author of his piece of work. Surely it was not so much to punish 
himself, although dissatisfaction with oneself is also a punishment. Much less obvious is Pygmalion's dissatisfaction with the fact that the external, man-made appearance of an ideal turned out to be not so ideal.

What is the result? There was an ideal, as a presentation of female perfection, and there appeared an idea, as an intention, as a purpose of activity to materialize the ideal. The purpose is achieved, but there is no satisfaction. The ideal of Pygmalion, as of the corporal creature, did not satisfy him absolutely: he needed the corporality of an ideal. In other words, he needed to see the ideal as not the "inner purpose", but as the corporality, quite touchable and implemented outside himself.

Consequently, an ideal, as an image of something perfect, precedes an idea. A human can live for a while without trying to implement his ideal, perceiving it as a dream, a product of imagination, which is beyond his ability to fulfill. However, even a dream is something emerging, faintly outlined.

Seen through inner vision, the ideal gradually acquires the traits of reality, almost becoming tangible. The time, of course, plays a role here. An ideal, perceived intensely, but momentarily can make the whole body tremble, but only stay in memory afterwards. Perceived over a period of time, it becomes the main type of human activity, i.e. the idea of its implementation. This idea is a person's desire to create the ideal, to see it existing outside himself.

It is known, in antiquity, philosophers understood "appearance", "form" and " idea" as the origins of existence. There were great insights, determining the layers of world culture. The ascendancy of these origins is the ascendancy of culture over the spontaneity, including the one, contained in a man himself. The culture involves everything, that is formed, that is seen and executed. All of it presents, finally, a purpose of any cultural activity. It is necessary to suppose, that "appearance" is its origin, some minimum, a peculiar quantum of culture (Note 2). To speak about the form, but "appearance" better expresses the idea of culture as a sphere of human activity, as it presupposes the existence of the one who sees as a subject. The form is a more aloof notion; it is, at least, permissible, even if a man is absent. Besides, the fact, how a man perceives himself is important in culture. A man himself is an appearance, whose peculiarity is to see. The man is simultaneously the appearance, and the one, who sees, but what is seen externally overshadows his own appearance. As a result, he stays an idea for himself, which serves as a generating model of culture-creating activity. The idea of appearance, consequently, is the idea of culture. The last one presents a process of an idea formation, i.e. its transformation into images, into observed values, and, as it seems, into ideals. In this sense, culture is a process of creation or acquisition of appearance, which is not always humane, as a man frequently exists for himself only as an idea. All creativity in culture is an effort to see and to make the observed accessible to everyone.

Thus, culture is not just a type of human activity; its product is the human as a species. The unique feature of the latter is not that the human is active or reasonable, but that he is capable of manifesting, or reproducing himself in the form of external phenomena. Culture is a way for the human being to see and understand himself. The more he is involved in observation, the less substantial it is. The perceived images are fascinating and bewitching; they determine the activity of the observer, making it increasingly abstract and aloof.

At this point, it is possible to draw an analogy with the law of the reverse scope-to-content ratio of a concept: the more substantial the observation is, the less a man depends on it and, consequently, the more he becomes himself. Vice versa, the quantitative power of the scope of the 
observed is the power of the surroundings over a man, reducing the substantiality of the latter, resulting in the loss of his own vision. In other words, in order to see in reality it is necessary not to see. It is not by chance that ancient visionaries were blind; neither is it an accident that Democritus, according to legend, made himself blind.

V.S. Solovyev assumed that the law of the reverse ratio is not applicable to ideas. The reason is that the notion is formed by means of an abstraction of features, resulting in its inanity. The idea is being formed by means of attraction of new features, filling it with new formations. That is why the bulk and content of an idea are in direct ratio (Solovyev 1989, pp. 123-124). It is possible to agree with this judgment of the philosopher, but applying it to the notion of an ideal. Concerning an idea, for example, of kindness, it differs from the similar notion with its aspiration for the corresponding ideal, which, as was mentioned above, is typical for it.

However, this aspiration can be regarded as something opposite: we do not drive for an ideal, it attracts and tempts us. It is weightier than our direct environment, that is why it as if distorts the space of our life in such a way, that it turns out to be in the center, invisible for the others. An ideal obliges us to conform, to assimilate to it, to exist, as it is an ideal, that seems to be true but not a kind of apparent existence. However, the irony (of our fate or nature) is such, that, the same as in the history about Pygmalion, we oblige to exist not ourselves, but an ideal.

What does it mean "to oblige to exist?" It is known, that specific human demands involve the demand to worship, to adore. It is directly conditioned by culture, as "worship" is included to the number of initial meanings of the relevant term. The man usually considers the value, satisfying such demand, as an ideal, i.e. as a limit of his drives, wishes, dreams etc. However, a man, as it was mentioned, is at least an appearance of culture, the number of his demands involves an initial demand - to see. The developed consciousness is quite satisfied with the subjective reality, i.e. observes an ideal as something sublime in him. It does not idealize and does not endue the existing cultural values with the features of an ideal. The underdeveloped consciousness behaves in a different way. Its typical feature is the persuasion in unreality of subjectiveness it presents the brightest characteristic of the underdevelopment. Such persuasion, as some scientists assumed, is the example of "the most absurd scientific misconception of the XX century" (Vilyunas, 1990). The persuasion in unreality of subjectiveness results in the natural conclusion about the necessity of an objective ideal, existing apart from consciousness. Finally, it is found in the form of the thing, which gets the required features, or in the form of the person as an object of worship. Anyhow, a man in culture obliges an ideal to exist and to be apparent apart from him. It is the essence of culture-creating activity.

However, the obvious ideal, within the time, becomes its visibility. It should be said that it does not appear at once in that negative meaning of the notion of "visibility", prescribed in philosophy. Speaking, for instance, about hearing, we do not bear in mind something illusive. The same is with visibility: first of all, it means the possibility to see something. In this case, visibility is referred to objects, enduing them with the feature to be seen better or worse. Visibility can mean simple reality of an object, and the regime of its perception. Finally, visibility is the appearance, mainly deceptive, i.e. a vision. In this ordinary understanding of visibility, it can be presented, on the one hand, as a deceit, and on the other hand, as a game of imagination or spirit, described by Kant (1991, pp. 52-62).

Visibility, consequently, turns out to be a bulky notion. It is not for nothing, that the creation of visibility, if it is intended or not, is typical for any activity, including the cogitative one. Visibility appears, when our ability to see turns into the visibility of the surrounding world. In other words, visibility is a human ability to see. That is why the world, perceived by a man, is 
presented as his picture, and the invisible, not given at the moment directly in consciousness, gets the features of visibility as a result of activity.

Cognition itself results in doubts about the significance of the observed things, to the persuasion, if it is the visibility. The same is with an ideal: critical, reflexive relation to it generates the doubt in its veracity. Now it will not be perceived as something sublime, worthy to be worshiped. In everyday life, if we find non-ideal sides in an subject, perceived as an ideal, it results in disappointment. Something similar can be observed in scientific cognition. Firstly, science as a whole, as a type of activity, is an ideal of cognition for the scientific community. In particular, a definite paradigm can serve as such an ideal; its followers idealize, as a rule, its cognitive abilities. Secondly, the philosophy of science distinguishes an ideal, or the criteria of scientific character. They involve either the degree of mathematization, or the main characteristics of scientific knowledge itself, such as systematic character, substantiation, feasibility etc. Finally, the acquisition of truth can be considered as an ideal of science itself. To be more precise: "to see everything as it is". The founders of science of the new time strove for it; they assumed that the world, observed directly, is the visibility of the true, ideal world, created by the God.

Within some time, however, the classical science, for instance, perceived as an ideal one, shows its limitedness, and turns out to be just an approach to the more complex - non-classical or post-classical - science. The same happens with paradigms and ideals of scientific character, as well as the "true" world, invisible till some time. The ideals of cognition stop to satisfy, they are replaced by the observation of something new, later perceived as visibility. This is the dynamics of not only scientific cognition, but the culture as a whole.

The nature of ideal can be understood only in its correlation with an idol. They both express human desire to see, but an idol is something created - a man-made ideal. In other words, between an ideal and an idol there appears the space of physical or human activity, which results in copying an ideal. The man wants to see the ideal, he makes it his purpose, and it becomes the reason of an idol appearance. When the purpose is achieved, he experiences either disappointment or enravishment with the appearance of an ideal, i.e. an idol. In consciousness, idols exist in the form of stagnant persuasions, prejudices, delusions, described by F. Bacon.

Creativeness of an ideal is determined by its structure - the unity of such values as truth, kindness and beauty. A man is able to create each of these values, but he is almost unable to unite them into something general. The drive for a separate implementation of truth, kindness and beauty conditions the appearance of the relevant idols. The problem of emergence, the source of ideals is connected with it.

This problem can be contradictive in itself: an ideal can be given to a man neither externally, where only idols exist, not internally, i.e. where there is imagination, where are the same idols, but in the forms of fantasies, chimeras, falsehood. The role of such "external-internal" in a person is presented by feelings, including truth, kindness and beauty.

One can hardly find a more impressive literary description of a source of the ideal than the one depicted by Fyodor Dostoevsky in his The Brothers Karamazov (1880). At the end of the novel, Alyosha, after Ilusha's funeral, addressed the boys,

"You must know that there is nothing higher and stronger and more wholesome and good for life in the future than some good memory, especially a memory of childhood, of home... If a man carries many such memories with him into life, he is safe to the end of his days, and if one has only one good memory left in one's heart, even that may sometime be the means of saving us." (Dostoevsky 2009, p. 1003) 
The quoted passage is about a memory, not the ideal, but the two are essentially related in this context: memories usually idealize the past, presenting it as something true, kind and beautiful, i.e. as an ideal.

There are two conclusions to the discussion presented in this article. Firstly, an ideal is a new experience of such states, as truth, kindness and beauty. We treat them as something objective, existing apart from our consciousness. However, as we experience all these states, we are to consider them as our own, not borrowed. That is why we perceive them as the ultimate truth, assuming that they are given to us from above.

Secondly, a man is predisposed to his past, therefore, he idealizes it, frequently making it the source of his ideals (Polishchuk 2012, p. 10). He also idealizes the future, but, as a rule, judging it from the past. It is proved both by the history of culture and by a dissatisfaction with it. In the past a man finds his ideals, which revive human values in him and determine his future (Hegel 1909, p. 334).

\section{Notes}

1. The fact that "appearance" and "idea" (ideal) are synonymous is proved by different translations of one and the same fragment of Plato's dialogue Timey (51e-52a): in the translation by S.S. Averintsev, it refers to an idea, and in the translation by A.N. Chanyshev it means "appearance".

2. "Appearance" here is used not in the meaning of "a subdivision in systematics (a species) included in the higher section of a genus", but in the meaning "the initial look and image of culture".

\section{References}

Dostoyevsky, Fyodor M. (2009). The Brothers Karamazov. Trans. Constance Garnett. The Lowell Press: New York.

Hegel, G. W. F. (1909) Phänomenologie des Geistes. Leipzig, Hrsg. von Otto Weiß.

Ilyenkov, Evald V. (1968). On Idols and Ideals. Moscow: Krasnyi Proletarii.

Kant, Immanuel. (1991). The Tartu manuscript. In Aesthetics of Immanuel Kant and Modernity. Moscow: Znaniye. 55-62.

Polishchuk, Viktor I. (2012). Three Answers to the Question of the Human. In Psychology and Psychotechnics, 3 (42).

Schelling, Friedrich W. J. von. (1987). System of Transcendentalism. In Selected Works in Two Volumes. Vol. 1. Moscow: Mysl. 227-489.

Solovyev, Vladimir S. (1989). Lectures on the History of Philosophy. In The Problems of Philosophy, 6.

Solovyev, Vladimir S. (1995). Idols and Ideals. In The meaning of life in Russian philosophy. St. Petersburg. 220-258.

Vilyunas, Vitis K. (1990). Psychological Mechanisms of Human Motivation. Moscow: MGU Press. 